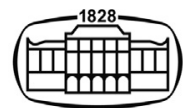

AKADÉMIAI KIADÓ

Journal of Behavioral Addictions

DOI:

$10.1556 / 2006.2021 .00075$

(c) 2021 The Author(s)

\section{COMMENTARY}

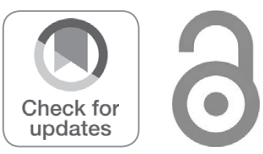

\title{
Draconian policy measures are unlikely to prevent disordered gaming
}

\author{
MICHELLE COLDER CARRAS ${ }^{1 *} \odot$, \\ VASILEIOS STAVROPOULOS ${ }^{2,3} \odot$, \\ FROSSO MOTTI-STEFANIDI ${ }^{3} \odot$, ALAIN LABRIQUE $^{1} \odot$ and \\ MARK D. GRIFFITHS ${ }^{4} \odot$
}

\author{
${ }^{1}$ Department of International Health, Johns Hopkins Bloomberg School of Public Health, \& Johns \\ Hopkins University Global Digital Health Initiative, Baltimore, MD, USA \\ ${ }^{2}$ Institute for Health and Sport, Victoria University, Melbourne, Australia \\ ${ }^{3}$ Department of Psychology, National and Kapodistrian University of Athens, Athens, Greece \\ ${ }^{4}$ International Gaming Research Unit, Psychology Department, Nottingham Trent University, \\ Nottingham, UK
}

Received: September 25, 2021 • Revised manuscript received: October 7, 2021 • Accepted: October 9, 2021

\begin{abstract}
In August of 2021, China imposed severe restrictions on children's online gaming time. We argue that such a policy may seem useful on the surface but does not reflect the current evidence concerning prevention of disordered gaming. Videogame play is normal for children worldwide, and like other leisure activities can lead to benefits for the majority and problems for a minority. Problematic or disordered play results from the interaction of multiple risk factors that are not addressed by draconian policy measures. Identifying these factors through stakeholder-engaged research and current evidence will be much more likely to succeed in preventing disordered gaming and promoting youth wellbeing.
\end{abstract}

\section{KEYWORDS}

Internet gaming disorder, children and adolescents, policy, government regulation, prevention, video games

\section{DRACONIAN POLICY MEASURES ARE UNLIKELY TO PREVENT DISORDERED GAMING}

In 2019, the Chinese government imposed significant restrictions on minors' online videogame play out of concerns regarding gaming addiction (State Council Information Office of the People's Republic of China, 2019). These new regulations limited underage gamers to 90 minutes of gaming on weekdays and three hours on weekends and holidays, with a complete ban on gaming between $10 \mathrm{pm}$ and $8 \mathrm{am}$. Citing continuing concerns by parents that these restrictions were not sufficient to reduce problems related to online gaming (Shin, 2021), the government reduced time even further in August 2021 to a limit of one hour of play only on Friday, Saturday and Sunday, with the frequency and intensity of government inspections of online gaming companies increased to ensure compliance (Goh, 2021). Such policies reflect a perspective that gaming is intrinsically negative without taking into the role of gaming in normal development and how differences between gamers in their unique gaming contexts may account for the diverse impact of gaming experiences over time (Stavropoulos, Gomez, \& Griffiths, 2021; Stavropoulos, Kuss, Griffiths, Wilson, \& Motti-Stefanidi, 2017). Such policies seem to deny evidence for the many benefits that moderate gaming involvement can bring from educational, health, cognitive, and therapeutic perspectives (Colder Carras, Van Rooij, et al., 2018; Griffiths, 2019; Nuyens, Kuss, Lopez-Fernandez, \& Griffiths, 2019) and also fail to address the need to 
consider disordered gaming as a maladaptive solution to another problem (Brown, Stavropoulos, Christidi, Papastefanou, \& Matsa, 2021; Kardefelt Winther, 2014).

Both changes in technology and advances in gaming disorder research point to the need for prevention and policy that take a nuanced approach. Cutting-edge advancements in internet gaming such as increased possibilities for interactions between gamers and game worlds and the use of algorithms that tailor one's gaming experience to their user profile have led to a boom in internet gaming (Stavropoulos, Motti-Stefanidi, \& Griffiths, 2021). This expansion in popularity of internet gaming has precipitated an impassioned dialogue regarding the possible benefits of gaming in relation to its likely deleterious impact (Raith et al., 2021; Richard, Temcheff, \& Derevensky, 2020). While older public health approaches mostly segregated gaming as either being inherently "good" and/or "bad" for gamers, newer research findings point to the necessity of determining how differences between gamers, including individual factors, in-game experiences, and out-of-game context, and their interactions over time, may generate diverse outcomes (Stavropoulos, Motti-Stefanidi, \& Griffiths, 2021).

Most gamers benefit through online gaming. It may promote their socialization, cognitive skills, and the development of dexterity (Colder Carras, Van Rooij, et al., 2018; Raith et al., 2021). In contrast, a relative few may lose control over their gaming, which may have detrimental consequences for their mental health and functioning (Richard et al., 2020; Stavropoulos, Motti-Stefanidi, \& Griffiths, 2021). For these individuals, excessive gaming may be a way to cope with existing problems such as low social competence, depression, anxiety, and dysfunctional family relationships or to stave off severe symptoms such as suicidal thoughts or substance cravings (Colder Carras, Kalbarczyk, et al., 2018; Hygen, Belsky, et al., 2020; Hygen, Skalická, et al., 2020; Li, Garland, \& Howard, 2014).

Although guidelines exist that address screen time in general and focus on balancing screen and other activities (e.g., Chassiakos et al., 2016), there is no consensus on the acceptable amount of videogame play for children and adolescents. One study of European adolescents suggested that those who played for two or more hours a day had twice the odds of having dysfunctional internet behavior, but the same levels of social networking use were associated with three times the odds (Tsitsika et al., 2014). A large representative sample of children in the United Kingdom found that those who played videogames between one and three hours a day had similar levels of wellbeing as those who did not play games at all (Przybylski, 2014). Although those seeking treatment for internet addiction played for six to seven hours a day in one sample (Müller, Beutel, \& Wölfling, 2014), a case series demonstrates that even gaming for fourteen hours a day is not necessarily indicative of addiction, e.g., if temporary and the gamer is able to cut back when competing demands arise (Griffiths, 2010). These considerations point to the vital need to adopt a multifaceted and individualized view when designing and implementing prevention and intervention policies. Such policies must not focus only on gaming time, but also address risk factors of disordered gaming and capitalize on the range of benefits for all types of gamers (Király, Tóth, Urbán, Demetrovics, \& Maraz, 2017).

Thus, draconian policy measures to reduce time spent gaming may seem useful on the surface, but don't reflect current theory and knowledge about prevention of problematic or disordered digital media use (Stavropoulos, Motti-Stefanidi, \& Griffiths, 2021) and often fail to work at all (Koh, 2015). According to one systematic review, the idea that simply reducing time spent playing games will reduce problematic gaming is "deeply misleading" (Király et al., 2018). Such strict regulations that limit personal freedoms will be difficult to enforce, and recent news articles indicate that even measures such as facial recognition systems are already being fooled (Borak, 2020; Lee, Kim, \& Lee, 2019; Shen, 2021). A similar approach in preventing youth gambling is age restrictions, which have little empirical support for their effectiveness and have been shown to be difficult to enforce (Shi, Colder Carras, Potenza, \& Turner, 2021). Policies that address only the time spent playing also fail to consider the role of online gaming in the normative development of children and may provoke reactance and excessive gaming in adulthood (Hygen, Skalická, et al., 2020). Most importantly, policies such as these may fail to address the other contributing factors that may lead individuals to use gaming as a coping mechanism, which runs the risk of driving youth to other maladaptive coping methods such as substance use (Hsu \& Marlatt, 2012).

Concerns about the extent to which cultural differences drive gaming-related research and policy have been expressed in the gaming disorder literature (Király et al., 2018; Stavropoulos et al., 2020). For instance, in South East Asia, parents tend to pathologize any online leisure activities that take time away from family and/or educational activities (Griffiths, Kuss, Billieux, \& Pontes, 2016). In China specifically, internet addiction has been associated with familylevel risk factors such as psychological and physical abuse, which suggests that Chinese adolescents may use the internet to cope with difficult and uncontrollable life situations (Li et al., 2014).

As Solon in 594 BCE had to revise the Draconian constitution to allow ancient Athens to flourish socially, politically and financially (Lape, 2002), draconian gaming measures implemented in China may need to be revised to enhance the wellbeing of children and adolescents. Indeed, Draco's laws in ancient Athens, as the currently introduced Chinese policies, tended to rigidly and horizontally impose the same severe punishment (in Draco's case the death penalty) across a series of minor and major offences whilst ignoring their substantial differences and providing no right of appeal. Acknowledging the lack of a differential and caseby-case approach, Solon varied the sentences imposed and provided the right to appeal for those who felt that their circumstances deserved alternative treatment (Rhodes, 2006).

The success of policy measures can be increased through collaborative approaches that are both culturally aware and sensitive (Hudson, Hunter, \& Peckham, 2019; O’Farrell, 
Baynes, Pontes, Griffiths, \& Stavropoulos, 2020). More specifically, stakeholder-engaged and community-based research may improve the outcomes of applied empirical findings and promote their successful adoption in public health interventions and population health (Freudenberg \& Tsui, 2014; Katapally, 2019). Previous research with gamer stakeholders demonstrates their willingness to discuss problems such as gaming disorder and to provide their own recommendations for interventions. For example, small studies with gamer stakeholders (i.e., gamers who attended gaming fan conventions) identified a specific game feature that promoted excessive play (i.e., appointment mechanics, a game feature that requires players to $\log$ in at a specific time to receive some award or be able to take a specific action, Kim, 2015) as well as a novel target for a preventive intervention (peer support for recognizing and preventing prolonged play periods; Colder Carras, Carras, \& Labrique, 2020; Colder Carras, Porter, et al., 2018). This suggests that involvement of voices from the ground up can help inform interventions that would be acceptable and effective in the population for which they are designed.

As we have shown here, evidence consistently suggests that identifying all contextual factors in an appropriate cultural context, rather than focusing exclusively on reducing access to the "pull factors" of digital and gaming media itself, stands a much better chance of reducing disordered gaming risk (Stavropoulos, Motti-Stefanidi, \& Griffiths, 2021). Many empirical evaluations of policy and programmatic interventions to prevent problematic gaming exist (King et al., 2018; Király et al., 2018, 2020; Throuvala, Griffiths, Rennoldson, \& Kuss, 2019), and these evidencebased reviews, when combined with appropriate stakeholder and community-engaged research, are most likely to promote the development and implementation of successful prevention interventions and policy.

Funding sources: VS: Australian Research Council, Discovery Early Career Researcher Aw, Grant/Award Number: DE210101107. No other financial support was received for this article.

Authors' contributions: MCC wrote the first draft of the paper and worked with the other co-authors on subsequent drafts. All authors contributed to the editorial process and have approved the final submitted version of the manuscript.

Conflict of interest: MCC consults with various companies around videogames and wellbeing and is the CEO and founder of Gaming and Wellness Association, Inc., a nonprofit organization dedicated to research and education about healthy videogame play. MDG's university currently receives funding from Norsk Tipping (the gambling operator owned by the Norwegian Government) for research evaluating responsible gambling tools in Norway. MDG has received funding for a number of research projects in the area of gambling education for young people, social responsibility in gambling and gambling treatment from Gamble Aware (formerly the Responsibility in Gambling Trust), a charitable body which funds its research program based on donations from the gambling industry. MDG also undertakes consultancy for various gaming companies in the area of social responsibility in gambling. AL, FMS, and VS declare no conflict of interest.

Ethics: This commentary article does not involve human participants.

\section{REFERENCES}

Borak, M. (2020, June 29). China's kids are coming up with creative ways to keep playing games. South China Morning Post. Retrieved October 6, 2021, from https://www.scmp.com/ abacus/games/article/3090778/fake-ids-and-smartphonearcades-how-kids-china-defy-anti-addiction.

Brown, T., Stavropoulos, V., Christidi, S., Papastefanou, Y., \& Matsa, K. (2021). Problematic internet use: The effect of comorbid psychopathology on treatment outcomes. Psychiatry Research, 298, 113789. https://doi.org/10.1016/j.psychres.2021.113789.

Chassiakos, Y. L. R., Radesky, J., Christakis, D., Moreno, M. A., Cross, C., \& Council on, Communication and Media (2016). Children and adolescents and digital media. Pediatrics, 138(5), e20162593. https://doi.org/10.1542/peds.2016-2593.

Colder Carras, M., Carras, M., \& Labrique, A. B. (2020). Stakeholders' consensus on strategies for self- and other-regulation of video game play: A mixed methods study. International Journal of Environmental Research and Public Health, 17(11), 3846. https://doi.org/10.3390/ijerph17113846.

Colder Carras, M., Kalbarczyk, A., Wells, K., Banks, J., Kowert, R., Gillespie, C., \& Latkin, C. (2018). Connection, meaning, and distraction: A qualitative study of video game play and mental health recovery in veterans treated for mental and/or behavioral health problems. Social Science \& Medicine, 216, 124-132. https://doi.org/10.1016/j.socscimed.2018.08.044.

Colder Carras, M., Porter, A. M., Van Rooij, A. J., King, D., Lange, A., Carras, M., \& Labrique, A. (2018). Gamers' insights into the phenomenology of normal gaming and game "addiction": A mixed methods study. Computers in Human Behavior, 79, 238246. https://doi.org/10.1016/j.chb.2017.10.029.

Colder Carras, M., Van Rooij, A. J., Spruijt-Metz, D., Kvedar, J., Griffiths, M. D., Carabas, Y., \& Labrique, A. (2018). Commercial video games as therapy: A new research agenda to unlock the potential of a global pastime. Frontiers in Psychiatry, 8, 300. https://doi.org/10.3389/fpsyt.2017.00300.

Freudenberg, N., \& Tsui, E. (2014). Evidence, power, and policy change in community-based participatory research. American Journal of Public Health, 104(1), 11-14. https://doi.org/10.2105/ AJPH.2013.301471.

Goh, B. (2021August 31). Three hours a week: play time's over for China's young video gamers. Reuters. Retrieved October 6, 2021, from: https://www.reuters.com/world/china/china-rolls-outnew-rules-minors-online-gaming-xinhua-2021-08-30/. 
Griffiths, M. D. (2010). The role of context in online gaming excess and addiction: Some case study evidence. International Journal of Mental Health and Addiction, 8(1), 119-125. https://doi.org/ 10.1007/s11469-009-9229-x.

Griffiths, M. D. (2019). The therapeutic and health benefits of playing video games. In A. Attrill-Smith, C. Fulwood, M. Keep, \& D. J. Kuss (Eds), The Oxford handbook of cyberpsychology (pp. 485-505). Oxford University Press. https://www. oxfordhandbooks.com/view/10.1093/oxfordhb/9780198812746. 001.0001/oxfordhb-9780198812746-e-27.

Griffiths, M. D., Kuss, D. J., Billieux, J., \& Pontes, H. M. (2016). The evolution of internet addiction: A global perspective. Addictive Behaviors, 53, 193-195. https://doi.org/10.1016/j.addbeh.2015. 11.001.

Hsu, S. H., \& Marlatt, G. A. (2012). Addiction syndrome: Relapse and relapse prevention. In APA addiction syndrome handbook, Vol. 2: Recovery, prevention, and other issues (pp. 105-132). American Psychological Association. https://doi.org/10.1037/ 13750-005.

Hudson, B., Hunter, D., \& Peckham, S. (2019). Policy failure and the policy-implementation gap: Can policy support programs help? Policy Design and Practice, 2(1), 1-14. https://doi.org/10. 1080/25741292.2018.1540378.

Hygen, B. W., Belsky, J., Stenseng, F., Skalicka, V., Kvande, M. N., Zahl-Thanem, T., \& Wichstrøm, L. (2020). Time spent gaming and social competence in children: Reciprocal effects across childhood. Child Development, 91(3), 861-875. https://doi.org/ 10.1111/cdev.13243.

Hygen, B. W., Skalická, V., Stenseng, F., Belsky, J., Steinsbekk, S., \& Wichstrøm, L. (2020). The co-occurrence between symptoms of internet gaming disorder and psychiatric disorders in childhood and adolescence: Prospective relations or common causes?. Journal of Child Psychology and Psychiatry, and Allied Disciplines, 61(8), 890-898. https://doi.org/10.1111/jcpp.13289.

Kardefelt Winther, D. (2014). A conceptual and methodological critique of internet addiction research: Towards a model of compensatory internet use. Computers in Human Behavior, 31, 351-354. https://doi.org/10.1016/j.chb.2013.10.059.

Katapally, T. R. (2019). The SMART framework: Integration of citizen science, community-based participatory research, and systems science for population health science in the digital age. JMIR MHealth and UHealth, 7(8), e14056. https://doi.org/10. 2196/14056.

Kim, B. (2015). Chapter 3. Game mechanics, dynamics, and aesthetics. Library Technology Reports, 51(2), 17-19. https:// journals.ala.org/index.php/ltr/article/view/5630.

King, D. L., Delfabbro, P. H., Doh, Y. Y., Wu, A. M. S., Kuss, D. J., Pallesen, S., ... Sakuma, H. (2018). Policy and prevention approaches for disordered and hazardous gaming and internet use: An international perspective. Prevention Science, 19(2), 233-249. https://doi.org/10.1007/s11121-017-0813-1.

Király, O., Griffiths, M. D., King, D. L., Lee, H.-K., Lee, S.-Y., Bányai, F., ... Demetrovics, Z. (2018). Policy responses to problematic video game use: A systematic review of current measures and future possibilities. Journal of Behavioral Addictions, 7(3), 503-517. https://doi.org/10.1556/2006.6.2017.050.

Király, O., Potenza, M. N., Stein, D. J., King, D. L., Hodgins, D. C., Saunders, J. B., ..., Demetrovics, Z. (2020). Preventing problematic internet use during the COVID-19 pandemic: Consensus guidance. Comprehensive Psychiatry, 100, 152180. https://doi.org/10.1016/j.comppsych.2020.152180.

Király, O., Tóth, D., Urbán, R., Demetrovics, Z., \& Maraz, A. (2017). Intense video gaming is not essentially problematic. Psychology of Addictive Behaviors, 31(7), 807-817. https://doi. org/10.1037/adb0000316.

Koh, Y.-S. (2015). The Korean national policy for internet addiction. In C. Montag, \& M. Reuter (Eds), Internet addiction: Neuroscientific approaches and therapeutical interventions (pp. 219-233). Springer International Publishing. https://doi.org/10. 1007/978-3-319-07242-5_13.

Lape, S. (2002). Solon and the institution of the "Democratic" family form. The Classical Journal, 98(2), 117-139. https:// www.jstor.org/stable/3298017.

Lee, S.-Y., Kim, M. S., \& Lee, H. K. (2019). Prevention strategies and interventions for internet use disorders due to addictive behaviors based on an integrative conceptual model. Current Addiction Reports, 6(3), 303-312. https://doi.org/10.1007/ s40429-019-00265-z.

Li, W., Garland, E. L., \& Howard, M. O. (2014). Family factors in internet addiction among Chinese youth: A review of Englishand Chinese-language studies. Computers in Human Behavior, 31, 393-411. https://doi.org/10.1016/j.chb.2013.11.004.

Müller, K. W., Beutel, M. E., \& Wölfling, K. (2014). A contribution to the clinical characterization of internet addiction in a sample of treatment seekers: Validity of assessment, severity of psychopathology and type of co-morbidity. Comprehensive Psychiatry, 55(4), 770-777. https://doi.org/10.1016/j.comppsych. 2014.01.010.

Nuyens, F. M., Kuss, D. J., Lopez-Fernandez, O., \& Griffiths, M. D. (2019). The empirical analysis of non-problematic video gaming and cognitive skills: A systematic review. International Journal of Mental Health and Addiction, 17(2), 389-414. https://doi.org/10.1007/s11469-018-9946-0.

O’Farrell, D. L., Baynes, K.-L., Pontes, M., Griffiths, M. D., \& Stavropoulos, V. (2020). Depression and disordered gaming: Does culture matter? International Journal of Mental Health and Addiction, Advance online publication. https://doi.org/10. 1007/s11469-020-00231-1.

Przybylski, A. K. (2014). Electronic gaming and psychosocial adjustment. Pediatrics, 134(3), e716-e722. https://doi.org/10. 1542/peds.2013-4021.

Raith, L., Bignill, J., Stavropoulos, V., Millear, P., Allen, A., Stallman, H. M., ... Kannis-Dymand, L. (2021). Massively multiplayer online games and well-being: A systematic literature review. Frontiers in Psychology, 12, 2369. https://doi.org/10. 3389/fpsyg.2021.698799.

Rhodes, P. J. (2006, January 1). The reforms and laws of Solon: An optimistic view. Solon of Athens; Brill. Retrieved October 5, 2021, from: https://brill.com/view/book/edcoll/9789047408895/ B9789047408895-s011.xml.

Richard, J., Temcheff, C. E., \& Derevensky, J. L. (2020). Gaming disorder across the lifespan: A scoping review of longitudinal studies. Current Addiction Reports, 7(4), 561-587. https://doi. org/10.1007/s40429-020-00339-3.

Shen, X. (2021, September 10). Middle-aged honour of kings player baffles tencent. South China Morning Post. Retrieved October 5, 
2021, from: https://www.scmp.com/tech/big-tech/article/ 3148324/tencent-quandary-about-verification-workarounds60-year-old-player.

Shi, J., Colder Carras, M., Potenza, M. N., \& Turner, N. E. (2021). A perspective on age restrictions and other harm reduction approaches targeting youth online gambling, considering convergences of gambling and videogaming. Frontiers in Psychiatry, 11, 601712. https://doi.org/10.3389/fpsyt.2020.601712.

Shin, J. (2021, August 30). Resolutely prevent minors from indulging in online games-the relevant person in charge of the state press and publication administration answered the reporter's question on the "Notice on further strict management and practically preventing minors from indulging in online games [Chinese]. Retrieved October 5, 2021, from: Original: http://www.gov.cn/zhengce/2021-08/30/content_5634208.htm; https://web.archive.org/web/20210903080630/.

State Council Information Office of the People's Republic of China (2019, November 5). The national press and publication administration answered the question on the "Notice on preventing minors from addicting to online games" [Chinese]. Retrieved October 5, 2021, from: Original: http://www.scio.gov.cn/xwfbh/ qyxwfbh/Document/1667701/1667701.htm, permalinkhttps:// web.archive.org/web/20211005135843/http://www.scio.gov.cn/ xwfbh/qyxwfbh/Document/1667701/1667701.htm.

Stavropoulos, V., Baynes, K. L., O’Farrel, D. L., Gomez, R., Mueller, A., Yucel, M., \& Griffiths, M. D. (2020). Inattention and disordered gaming: Does culture matter? Psychiatric Quarterly, 91(2), 333-348. https://doi.org/10.1007/s11126-019-09702-8.

Stavropoulos, V., Gomez, R., \& Griffiths, M. D. (2021). In search of the optimum structural model for internet gaming disorder. BMC Psychiatry, 21(1), 176. https://doi.org/10.1186/s12888021-03148-8.

Stavropoulos, V., Kuss, D. J., Griffiths, M. D., Wilson, P., \& MottiStefanidi, F. (2017). MMORPG gaming and hostility predict internet addiction symptoms in adolescents: An empirical multilevel longitudinal study. Addictive Behaviors, 64, 294-300. https://doi.org/10.1016/j.addbeh.2015.09.001.

Stavropoulos, V., Motti-Stefanidi, F., \& Griffiths, M. D. (2021). Risks and opportunities for youth in the digital era. European Psychologist. Advance online publication https://doi.org/10. 1027/1016-9040/a000451.

Throuvala, M. A., Griffiths, M. D., Rennoldson, M., \& Kuss, D. J. (2019). School-based prevention for adolescent internet addiction: Prevention is the key. A systematic literature review. Current Neuropharmacology, 17(6), 507-525 psyh https://doi. org/10.2174/1570159X16666180813153806.

Tsitsika, A., Janikian, M., Schoenmakers, T. M., Tzavela, E. C., Olafsson, K., Wojcik, S., ... Richardson, C. (2014). Internet addictive behavior in adolescence: A cross-sectional study in seven European countries. Cyberpsychology, Behavior and Social Networking, 17(8), 528-535. https://doi.org/10.1089/cyber.2013. 0382. 